\title{
PENERAPAN KONSEP FINITE STATE AUTOMATA (FSA) PADA VENDING MACHINE VOUCHER INTERNET CORNER
}

\author{
Ilham Wahyudi Siadi ${ }^{1}$, Kukuh Panggalih ${ }^{2}$, Ahmad Bayhaqqi $^{3}$, Windu Gata ${ }^{4}$ \\ Ilmu Komputer, Universitas Nusa Mandiri \\ 14207026@nusamandiri.ac.id,14207107@nusamandiri.ac.id, ahmadbayhaqqi@nusamandiri.ac.id, \\ windu@nusamandiri.ac.id
}

Submitted July 15, 2021; Revised November 29, 2021; Accepted December 1, 2021

\begin{abstract}
Abstrak
Saat ini Internet sudah banyak digunakan oleh semua kalangan bahkan anak kecil pun sudah mengenal Internet. Namun ada beberapa tempat yang masih saja tidak terjangkau oleh sinyal Internet yang memadai. Maka dari itu dari penelitian ini memungkian untuk pembuatan Vending Machine yang dimana Vending Machine tersebut menyediakan berbagai macam paket Internet yang beragam yang bisa digunakan ditempat-tempat yang sudah disediakan yang tentunya strategis. Untuk metode penelitiannya disini menggunakan Finite State Automata. Selain itu harga nya pun sangat terjangkau dan sangat membantu pengguna Internet untuk mendapat akses Internet secara layak ditempat-tempat yang sinyal nya sangat tidak memadai untuk penggunaan Internet. Setelah pruduk ini diuji coba dengan metode Finite State Automata dan diberikan kebeberapa sumber. Terlihat banyak respon yang cukup aktif dan semoga dapat membantu masyarakat dalam menikmati akses Internet.
\end{abstract}

Kata Kunci : Voucher, Internet, Finite, State, Automata

\begin{abstract}
The Internet today has been widely used by all circles, even young children are familiar with it. However, there are some places that are still not covered by an adequate Internet signal. Therefore, this research makes an effort to create a Vending Machine that can provide a variety of Internet packages that can be used in certainly strategic places. In addition, the machine charges a very affordable price and it is very helpful for Internet users to get proper Internet access in places with very inadequate signal for Internet use. The research applies a Finite State Automata method. After this product is tested using the Finite State Automata method and given to several sources, it receives many quite positive responses, with the expectation it can help the community in enjoying Internet access.
\end{abstract}

Keywords : Voucher, Internet, Finite, State, Automata

\section{PENDAHULUAN}

Vending Machine merupakan suatu alat atau mesin yang menjual barang secara otomatis. Vending Machine tidak membutuhkan tenaga operator untuk menjual barang, konsumen dapat memilih sendiri barang yang diinginkan[1]. Contoh yang sudah banyak beredar adalah Vending Machine sebuah mesin penjual minuman yang dapat beroperasi secara standalone untuk melayani transaksi pembelian minuman atau makanan kecil [2].

Salah satu kendala dalam penjualan menggunakan Vending Machine adalah tidak adanya sistem pengembalian uang jika konsumen tidak mempunyai nominal mata uang sesuai dengan harga barang yang dijual pada Vending Machine, sehingga konsumen harus menyediakan uang pas agar dapat membeli barang yang ada pada Vending Machine tersebut [3]. Saat ini penggunaan $Q r$ Code sudah cukup luas. Banyak Negara di dunia, terutama Jepang, telah menerapkan teknologi $Q r$ Code pada industri. Sementara di Indonesia, $Q r$ Code sudah mulai diterapkan pada kuliner seperti pembelian makanan pada Vending Machine [4]. 
Saat sekarang ini sistem pembayaran Vending Machine dilakukan dengan scan Qr Code lewat kamera yang terpasang pada smartphone, untuk melakukan pembayaran lewat $Q r$ Code pengguna smartphone harus terlebih dahulu mengunduh aplikasi $e$-wallet atau mobile banking. Perkembangan teknologi dewasa ini sangat pesat salah satunya smartphone yang sangat berpengaruh pada bidang teknologi informasi.

Dalam pemanfaatannya smartphone dapat membaca $Q r$ Code salah satunya untuk mengidentifikasi jenis barang. $Q r$ Code adalah image dua dimensi yang merepresentasikan suatu data, terutama data berbentuk teks. $Q r$ Code merupakan evolusi dari barcode yang awalnya satu dimensi menjadi dua dimensi. Qr Code memiliki kemampuan menyimpan data yang lebih jauh besar daripada barcode[4]. Sementara berbelanja makanan pada food court sekarang ini masih secara manual dimana pembeli harus mengantri setelah mengambil makanan. Setelah melakukan pengantrian pembeli harus menunggu karena penjual akan melakukan pengecekan dan menghitung berapa harga yang harus dibayarkan. Hal ini menyebabkan antrian akan semakin panjang dan waktu yang dibutuhkan untuk pengambilan makanan akan semakin lama.

Namun ada beberapa food court yang menyediakan kartu yang telah berisi saldo, setiap pembeli akan menerima kartu sebelum berbelanja. Terlepas dari itu beberapa Vending Machine sudah banyak bermunculan. Mulai dari Vending Machine pembuatan kopi atau minuman dingin, ada juga Vending Maching pembelian rokok yang dimana pembeli diwajibkan mempunyai KTP untuk melakukan proses pembelian di Vending Machine tersebut. Ada juga Vending Machine pembuatan jamu tradisional, dimana Vending Machine tersebut membuat atau merakit jamu sesuai dengan permintaan si pembeli. Lalu ada juga Vending Machine pembelian emas atau logam mulia, yang dimana pembeli bisa membeli emas secara otomatis lewat Vending Machine yang tersedia. Dilihat dari contoh tersebut perkembangan Vending Machine di Indonesia sudah sangat pesat dan sangat mengagumkan sampai membuat kepala mengeleng-geleng rasanya.

Terlepas dari itu semua sebuah Vending Machine membutuhkan koneksi Internet agar dapat terkoneksi dengan server pusat. Melihat proses itu sudah tidak bisa dipungkiri lagi bahwa koneksi Internet sudah tidak dapat dipungkiri lagi bahwa merupakan suatu kebutuhan yang sangat penting. Bahkan ada beberapa cletuk netizen yang mengatakan bahwa lebih baik tidak makan dari pada tidak Internet an. Maka dari itu penelitian ini akan membahas Vending Machine pembelian Voucher Internet Corner. Vending Machine tersebut akan di letakkan ditempat tempat yang sangat strategis yang dimana disana banyak pengguna membutuhkan koneksi Internet yang cukup stabil. Misal di pusat perbelanjaan, di sekolah, di halte bus, bahkan ditempat wisata dan lain lain. Proses nya pengunaannya pun sangat mudah seperti Vending Machine pada umumnya, dimana pembeli hanya tinggal melakukan proses transaksi pembelian via Vending Machine tersebut, mulai dari pemilihan paket Internet berdasarkan kecepatan dan durasi penggunaan Internet atau bahkan berdasarkan aplikasi yang ingin digunakan. Lalu untuk pembayarannya hanya tinggal scan barcode yang sudah disediakan. Setelah proses pembayaran maka akan tampil username dan password untuk login di web yang sudah disediakan. Lalu pembeli bisa menikmati Internet yang sangat cepat dan juga stabil

Internet merupakan suatu kebutuhan yang sangat pending di era sekarang, dimana banyak anak kecil yang sudah melek 
internet bahkan hampir setiap hari aktifitas manusia dilakukan dengan menggunakan Internet.

Internet Corner merupakan suatu aplikasi dimana pengguna bisa menggunakan Internet dengan cara membeli nya pada Vending Machine yang sudah dirancang dengan teliti agar memudahkan manusia menggunakan Internet dimana pun dan kapan pun. Vending Machine yang sudah dirancang untuk memudahkan dimana pembeli bisa melakukan pembelian paket internet yang beragam dengan waktu penggunaan yang beragam, dan untuk pembayaran nya pun sudah cashless jadi sangat memudahkan dalam manajemen keuangan yang dimana biaya pembayaran langsung masuk ke akun rekening pusat.

Automata merupakan suatu sistem yang memiliki fungsi dan terdiri dari sejumlah state, setiap state menyatakan informasi mengenai input dan dapat juga disebut mesin abstrak yang dapat menerima input atau membangkitkan sebuah kalimat dalam bahasa tertentu.

Teori bahasa dan automata merupakan salah satu komponen ilmu informatika, teori ini merupakan ide dan model fundamental yang mendasari sebuah sistem komputasi, teori ini juga bisa disebut sebagai sebuah teknik rekayasa untuk perancangan sistem komputasi.

FSA adalah adalah model yang baik untuk komputer dengan kemampuan yang sangat terbatas jumlah memori . FSA merupakan model matematika dari suatu system yang dapat menerima dan menghasilkan output dan memiliki state yang berhingga banyaknya sehingga dapat berpindah dari state satu ke state lainnya dan terdiri dari $D F A$ dan NFA . Secara formal FSA dinyatakan oleh 5 tupel atau $\mathrm{M}=(\mathrm{Q}, \Sigma, \delta$, $\mathrm{S}, \mathrm{F})$ dimana:

$\mathrm{Q}=$ himpunan state/kedudukan

$\Sigma=$ himpunan simbol input/masukan/abjad $\delta=$ fungsi transisi
$\mathrm{S}=$ state awal/kedudukan awal (initial state),

$\mathrm{S} \in \mathrm{Q} F=$ himpunan state akhir, $\mathrm{F} \cap \mathrm{Q}$ (jumlah state

akhir pada suatu FSA bisa lebih dari satu)

\section{METODE PENELITIAN}

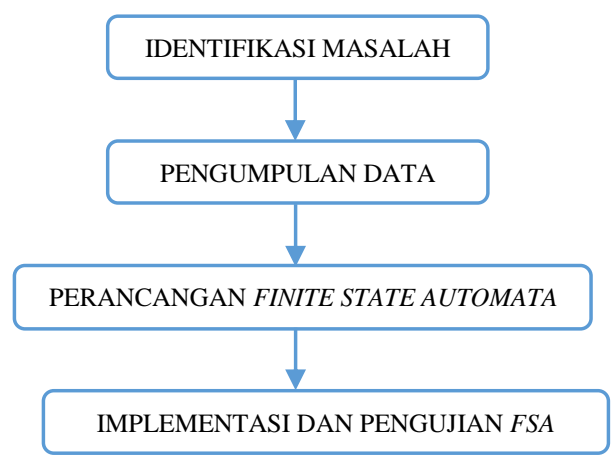

Gambar 1. Tahapan Penelitian

Tahap Pertama Identifikasi Masalah yaitu penting nya akses Internet dalam kehidupan sehari-hari. Namun masih sangat sulit untuk mendapatkan sinyal yang cepat pada tempat tertentu

Tahap Kedua Pengumpulan Data yaitu mengumpulkan data mengenai tempat tempat ramai atau strategis yang banyak penggunaan internet namun kondisi sinyal yang sangat tidak mendukung.

Tahap Ketiga Perancangan Finite State Automata yaitu membuat Vending Machine yang dimana pembeli bisa melakukan pembelian paket Internet berdasarkan kecepatan dan durasi pemakaian.

Tahap keempat Implementasi dan Pengujian FSA yaitu membuat sistem dengan mengimplementasikan Finite State Automana untuk mengatur voucher Internet yang dibeli oleh pengguna, serta menjalankan proses implementasi program serta menguji hasil output dari program dengan melihat hasil yang diberikan oleh pengguna sejenis testimoni atau feedback. 


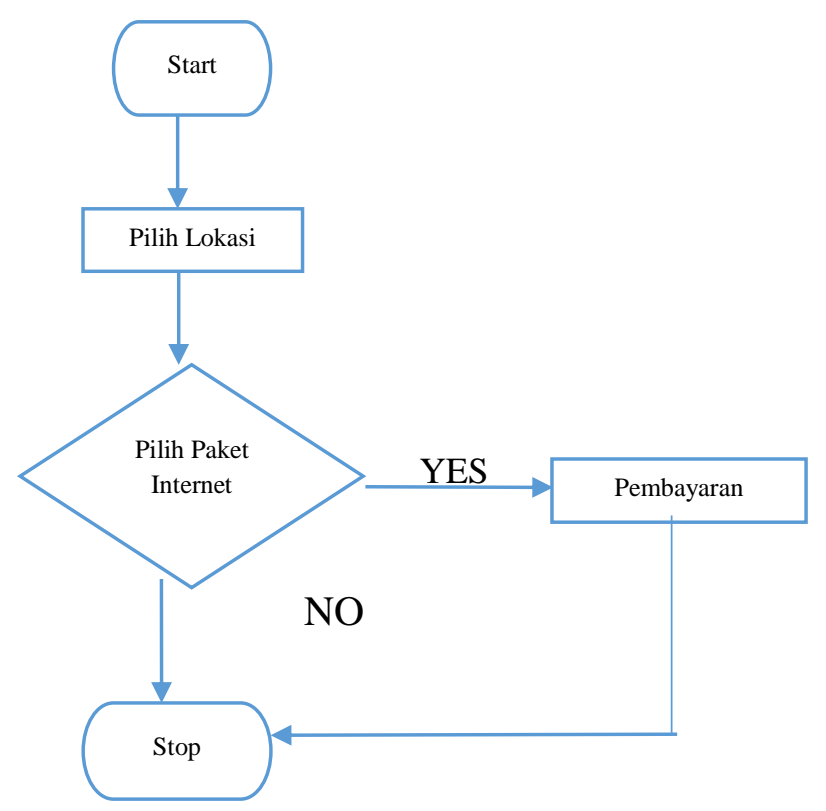

Gambar 2 . Proses Transaksi

Gambar merupakan kemungkinan dari proses transaksi pembelian paket voucher internet pada Vending Machine terdekat dalam bentuk flowchart. Selanjutnya flowchart akan digunakan sebagai bahan untuk merancang diagram state dan alur program.

\section{HASIL DAN PEMBAHASAN}

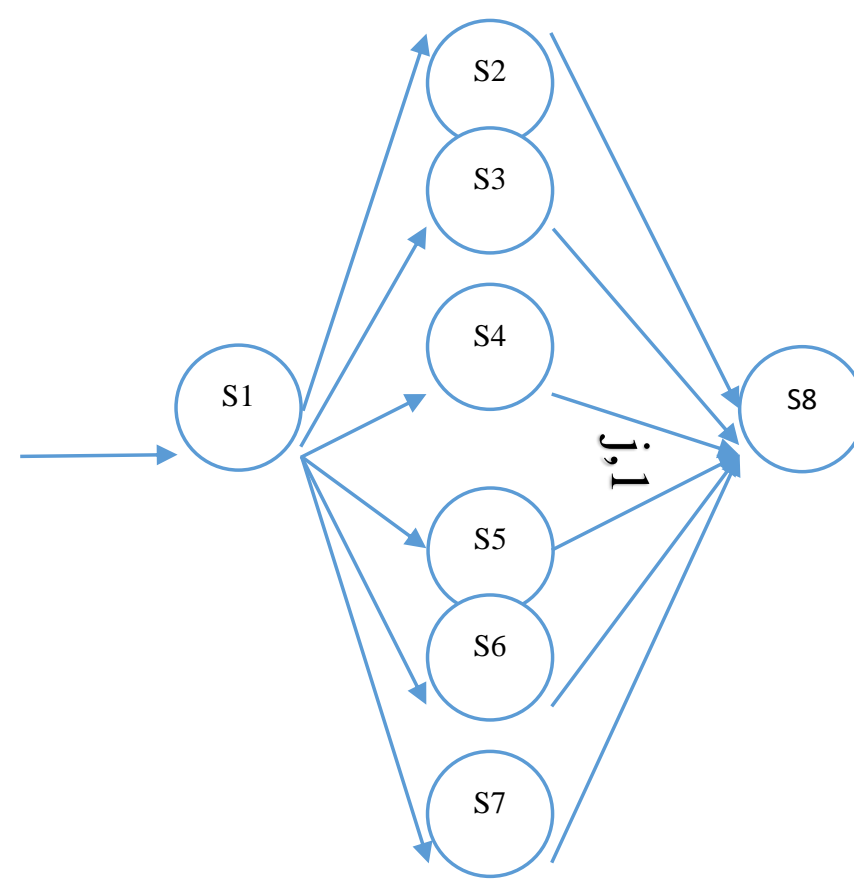

Gambar 3 . Rancangan Diagram
Gambar menunjukkan rancangan diagram N-DFA sistem pembelian Voucher Internet Corner dengan tuple sebagai berikut: $\mathrm{Q}=\{\mathrm{S} 1, \mathrm{~S} 2, \mathrm{~S} 3, \mathrm{~S} 4, \mathrm{~S} 5, \mathrm{~S} 6, \mathrm{~S} 7, \mathrm{~S} 8\}$ $\sum=\{\mathrm{j} 1\}$

$\mathrm{S}=\mathrm{S} 1$

$\mathrm{F}=\{\mathrm{S} 2, \mathrm{~S} 3, \mathrm{~S} 4, \mathrm{~S} 5, \mathrm{~S} 6, \mathrm{~S} 7, \mathrm{~S} 8\}$ $=\{((\mathrm{S} 1, \mathrm{~S} 2), \mathrm{S} 8),((\mathrm{S} 1, \mathrm{~S} 3), \mathrm{S} 8),((\mathrm{S} 1, \mathrm{~S} 4)$, S8), ((S1,S5), S8), ((S1, S6), S8), ((S1,S7), S8) $\}$

Ada 8 (delapan) state yaitu (S1) lokasi mesin, (S2) Internet Kilat 1, (S3) Internet Kilat 2, (S4) Internet Kilat 3, (S5) Internet Asik 1, (S6) Internet Asik 2, (S7) Internet Asik 3, (S8)Pembayaran.

Sedangkan input yang ada sebagai berikut: (j1) Scan Qris.

Hasil penelitian yang telah dilakukan dengan membagikan hasil penelitian dan bertanya ke beberapa sumber. Banyak respon positif yang menganggap bahwa hal ini kedepannya akan membuat masyarakat merasa nyaman dan mudah dalam menggunakan internet corner

\section{SIMPULAN}

Berdasarkan pembahasan Penerapan Konsep Finite State Automata (FSA) Pada Vending Machine Voucher Internet Corner yang dilakukan dapat di ambil bahwa penerapan Vending Machine pada Voucher Internet Corner sangat membantu untuk proses pembelian paket Internet yang dimana tempat-tempat tersebut sangat sulit untuk mendapat koneksi Internet yang stabil, jadi sangat memudahkan pengguna. Serta untuk pembayaran nya pun cukup mudah hanya tinggal scan $Q r$-Code yang sudah disediakan dan transfer uang pembayaran nya via aplikasi, pengguna langsung mendapatkan username dan password yang digunakan untuk login dilaman web yang sudah disediakan dan 
pengguna bisa menggunakan Internet yang cukup stabil dan cepat sesuai paket yang sudah dibeli.

\section{DAFTAR PUSTAKA}

[1] T. I. Saputra, F. Fauziah, and A. Gunaryati, "Simulasi Vending Machine Dengan Mengimplementasikan Finite State Automata," JOINTECS (Journal Inf. Technol. Comput. Sci., vol. 3, no. 3, pp. 143-148, 2018.

[2] K. Handayani, D. Ismunandar, S. A. Putri, and W. Gata, "Penerapan Finite StateAutomata Pada Vending Machine Susu Kambing Etawa," Matics, vol. 12, no. 2, pp.87-92, 2021.

[3] Sahrul, F. Karimah, A. Muhazabah, A. D. Prasetyo, A. Yunita, and N. L. Zahra, "Pengembangan Aplikasi Permainan 'Pilah Sampah' Menggunakan Pemodelan Finite State Machine," J. Teknol., vol. 1, no. 1, pp. 38-46, 2018.

[4] E. Sofyan, "Penerapan Metode MultiFactor Evaluation Process ( MFEP ) dan Algoritma Finite State Automata ( FSA ) untuk Pencarian Lokasi Kost Terdekat," J. Mhs. Apl. Teknol. Komput. dan Inf., vol. 2, no. $1,2020$.

[5] S. Tamara and H. Sasana, "Analisis Dampak Ekonomi Dan Sosial Akibat Kemacetan Lalu Lintas Di Jalan Raya Bogor-Jakarta," J. REP (Riset Ekon. Pembangunan), vol. 2, no. 2, pp. 185196, 2017.

[6] Graham, Robert David, and Peter C. Johnson. "Finite state machine parsing for internet protocols: Faster than you think." 2014 IEEE Security and Privacy Workshops. IEEE, 2014.

[7] Siadi, Ilham Wahyudi, Iskandar Fitri, and Rini Nuraini. "Tunneling Design with Point to Point Protocol over Ethernet (PPPoE) using Mikrotik RB941 (Case Study of SMK Taruna Bhakti): Tunneling Design with Point to Point Protocol over Ethernet (PPPoE) using Mikrotik RB-941 (Case Study of SMK Taruna Bhakti)." Jurnal Mantik 4.1 (2020): 238-247.

[8] Kozierok, Charles M. The TCP/IP guide: a comprehensive, illustrated Internet protocols reference. No Starch Press, 2005.

[9] Dallery, Jesse, and Irene M. Glenn. "Effects of an Internet-based voucher reinforcement program for smoking abstinence: A feasibility study." Journal of applied behavior analysis 38.3 (2005): 349-357.

[10] Glenn, Irene M., and Jesse Dallery. "Effects of internet-based voucher reinforcement and a transdermal nicotine patch on cigarette smoking." Journal of applied behavior analysis 40.1 (2007): 1-13.

[11] Brenna, Lars, et al. "Distributed event stream processing with nondeterministic finite automata." Proceedings of the Third ACM International Conference on Distributed Event-Based Systems. 2009.

[12]Fitria, Tiara Sukma, and Agus Prihanto. "Implementasi Generate Voucher Hotspot Dengan Batasan Waktu (Time Based) Dan Kuota (Quota Based) Menggunakan User Manager Di Mikrotik." Jurnal Manajemen Informatika 8.2 (2018). 